\title{
I 056 Feasibility and ultility of cardiac MRI in patients with valved bovine jugular vein conduits for right ventricular outflow tract reconstruction
}

\author{
Sabeena Ramrakhiani*1, Mervyn D Cohen², John W Brown ${ }^{3}$ and \\ Tiffanie R Johnson ${ }^{4}$
}

Address: ${ }^{1}$ Krannert Institute of Cardiology, Indianapolis, IN, USA, ${ }^{2}$ Department of Radiology, Riley Hospital for Children, Indiana University School of Medicine, Indianapolis, IN, USA, ${ }^{3}$ Department of Cardiothoracic Surgery, Indiana University School of Medicine, Indianapolis, IN, USA and ${ }^{4}$ Indiana University, Riley hospital for Children, Section of Pediatric Cardiology, Indianapolis, IN, USA

* Corresponding author

from I Ith Annual SCMR Scientific Sessions

Los Angeles, CA, USA. I-3 February 2008

Published: 22 October 2008

Journal of Cardiovascular Magnetic Resonance 2008, I0(Suppl I):AI8I doi:I0.II86/I532-429X-I0-SI-AI8I

This abstract is available from: http://jcmr-online.com/content/I0/SI/AI8I

(c) 2008 Ramrakhiani et al; licensee BioMed Central Ltd.

\section{Background}

Pulmonary homografts have been the most widely used valved conduits for right ventricular outflow tract (RVOT) reconstruction in the US since mid 1980s. In 1999 a conduit containing a bovine jugular vein (Contegra ${ }^{\circledR}$, Medtronic, Inc, Minneapolis, MN) was introduced as a potential alternative for RVOT reconstruction. In 2003, the bovine jugular vein conduit was released by the FDA for humanitarian device exemption (HDE) utilization in centers that obtain institutional review board approval and have appropriate informed patient consent. Main advantages of the Contegra ${ }^{\varpi}$ conduit include availability in sizes from $12-22 \mathrm{~mm}$, natural continuity between the valve and the conduit that allows proximal infundibular shaping without additional materials, lower price compared to about half of the pulmonary homografts in the US, and reduced potential risk of supravalvular stenosis due to narrowing at the distal suture line. This data has been reported based on echocardiographic findings of the Contegra ${ }^{\circledast}$ conduit postoperatively. We report on the use of cardiac magnetic resonance (CMR) in patients postoperatively and compare the findings with echocardiography.

\section{Methods}

We retrospectively analyzed the results of CMR performed pre- and postoperatively in 5 patients with the Contegra ${ }^{\circledR}$ conduit. CMR was performed using a 1.5 Tesla Siemens Avanto system (Siemens Medical solutions, Malvern, PA). Standard images for anatomical and functional evaluation, including volume and flow analysis were reviewed. Descriptive statistical analysis was performed.

\section{Results}

The mean age of patients was 20.2 years with average weight $116.7 \mathrm{lbs}$ and body surface area of 1.57 sq meters. There were 4 males and 1 female. Primary pathologies included tetralogy of Fallot $(\mathrm{n}=3)$, double outlet right ventricle with pulmonary atresia $(n=1)$ and complex single ventricle with pulmonary atresia $(n=1)$. The average time period between the placement of the Contegra ${ }^{\otimes}$ conduit and CMR was 12 months. The mean right ventricular end-diastolic volume to left ventricular end-diastolic volume ratio RVEDP: LVEDP) preoperatively was 1.6 and postoperatively was 1.3 . The conduit and the neo-pulmonic valve were well visualized on CMR in all 5 patients, whereas only 3 patients' echocardiograms were able to visualize the Contegra ${ }^{\circledast}$ conduit well. In addition, CMR was able to quantify the right ventricular function and degree of pulmonic regurgitation, if any. The conduit was not dilated in any of the 5 patients. Although minimal pulmonic regurgitation was noted on CMR in 3 of the 5 patients, this was significantly better than on the preoperative CMR. None of the patients experienced any complications 


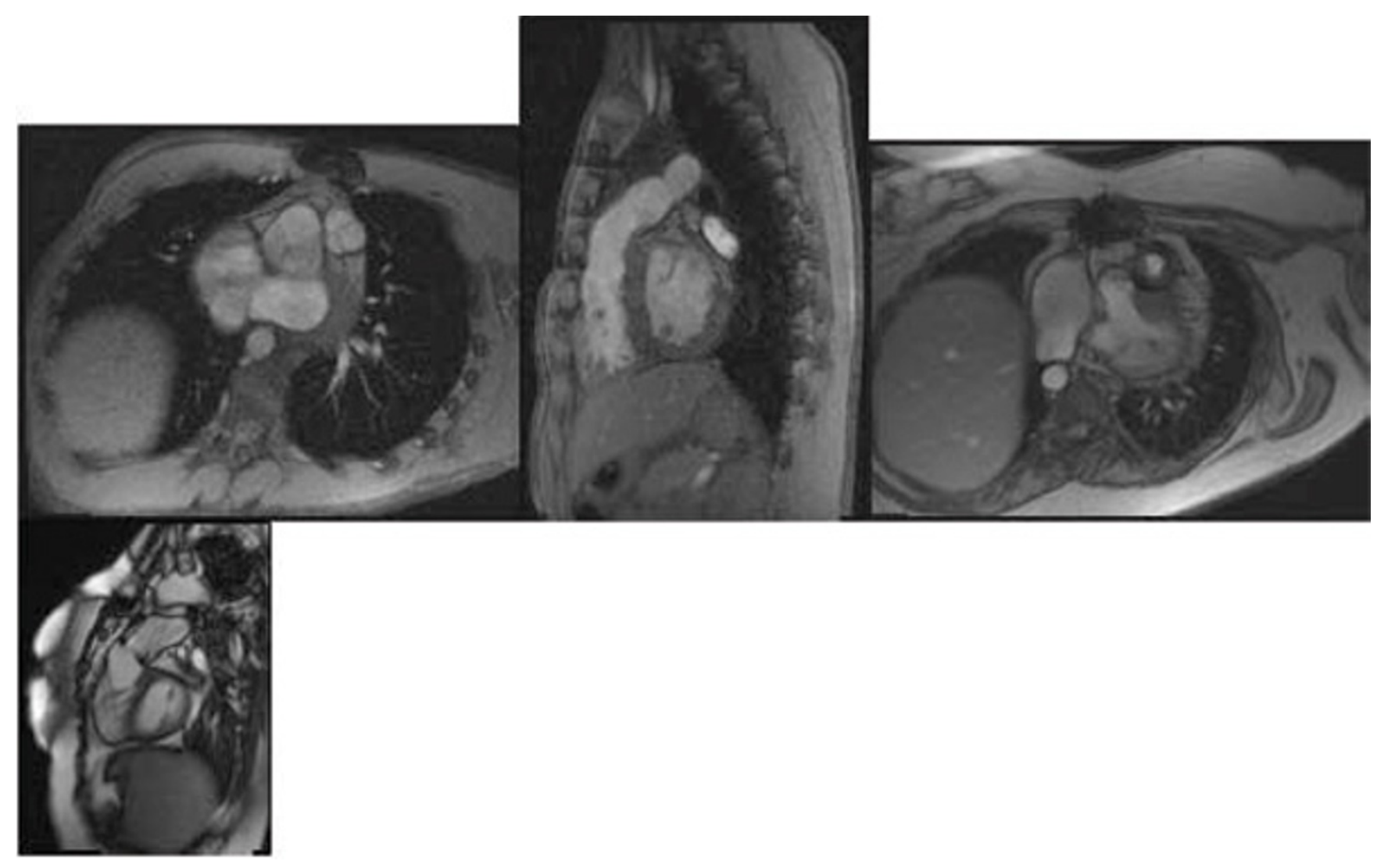

Figure I

Images I and 2 represent images from a patient with Contegra ${ }^{\circledR}$ conduit and images 3 and 4 are from a patient with a St. Jude Biocor $^{\circledR}$ porcine pulmonic valve.

related to the magnetic field. The quality of the images of the Contegra ${ }^{\circledast}$ conduit compared well with other prosthetic valves on CMR (Figure 1).

\section{Conclusion}

The Contegra ${ }^{\varpi}$ conduit is safe to image with CMR, even as early as a year postoperatively, CMR provides excellent images and reliable data regarding the functionality of the conduit with relative ease when compared to echocardiography. This is a promising alternative for following patients with RVOT reconstruction to assess the Contegra ${ }^{\oplus}$ conduit and neo-pulmonic valve, degree of pulmonary regurgitation or stenosis, and right ventricular function.
Publish with Biomed Central and every scientist can read your work free of charge

"BioMed Central will be the most significant development for disseminating the results of biomedical research in our lifetime."

Sir Paul Nurse, Cancer Research UK

Your research papers will be:

- available free of charge to the entire biomedical community

- peer reviewed and published immediately upon acceptance

- cited in PubMed and archived on PubMed Central

- yours - you keep the copyright
BiolMedcentral 